\title{
Paraphaeosphaeride $D$ and berkleasmin $F$, new circumventors of arbekacin resistance in MRSA, produced by Paraphaeosphaeria sp. TR-022
}

\author{
Takuya Suga $^{1}$, Mayu Shiina ${ }^{1}$, Yukihiro Asami ${ }^{1,2}$, Masato Iwatsuki ${ }^{1,2}$, Tsuyoshi Yamamoto ${ }^{2}$, Kenichi Nonaka ${ }^{2}$, \\ Rokuro Masuma ${ }^{1,2}$, Hidehito Matsui ${ }^{2}$, Hideaki Hanaki ${ }^{2}$, Susumu Iwamoto ${ }^{3}$, Hideyuki Onodera ${ }^{3}$, \\ Kazuro Shiomi $^{1,2}$ and Satoshi Ōmura ${ }^{2}$
}

Two new compounds, designated paraphaeosphaeride $D(1)$ and berkleasmin $F(2)$ together with a previously known compound, berkleasmin A (3), isolated from a culture broth of the fungus Paraphaeosphaeria sp. TR-022, proved to be new circumventors of arbekacin (ABK) resistance in methicillin-resistant Staphylococcus aureus (MRSA). The structures of 1 and 2 were elucidated by spectroscopic analyses, including various NMR experiments. All compounds showed 10-100 times ABK circumvention activities using the paper disc method and reduced the MIC values of ABK against MRSA from $16 \mu \mathrm{gl}^{-1}$ to $4 \mu \mathrm{g} \mathrm{ml}-1$ (fourfold) using the agar dilution method. These new compounds might be promising lead compounds for developing circumventors of ABK resistance in MRSA.

The Journal of Antibiotics (2016) 69, 605-610; doi:10.1038/ja.2016.70; published online 22 June 2016

\section{INTRODUCTION}

The World Health Organization has recently classified antibiotic resistance as one of the three greatest threats to human health. In particular, methicillin-resistant Staphylococcus aureus (MRSA) has an important role in causing serious nosocomial infection. ${ }^{1}$ Launched in Japan at the end of 1990, arbekacin (ABK) is a useful chemotherapeutic agent for the treatment of infections caused by MRSA. 2,3 Soon after it was launched, it was reported that a few percent of MRSA strains were resistant to ABK. Therefore, to maintain the usefulness for the drug, it is important to develop a new agent that helps overcome ABK resistance in MRSA. ${ }^{4,5}$ The main mechanism of resistance to aminoglycosides, including $A B K$, is thought to be via inactivation by enzymatic modification. In particular, the bifunctional enzyme $\mathrm{AAC}\left(6^{\prime}\right)-\mathrm{Ie} / \mathrm{APH}\left(2^{\prime \prime}\right)$-Ia is thought to play a crucial role in ABK resistance in MRSA, which can catalyze both phosphorylation at 2 "-hydroxyl and acetylation at 6'-amino group of aminoglycosides. ${ }^{6}$ Consequently, specific inhibitors against this enzyme should help maintain ABK's effectiveness.

During our screening for new circumventors of ABK resistance, we have already found biverlactones, aranorosin and aogacillins among fungal metabolites. ${ }^{7-9}$ Our continuing search has now led to the discovery of two new compounds, named paraphaeosphaeride D (1) and berkleasmin F (2), from a culture broth of the fungus, Paraphaeosphaeria sp. TR-022, together with a known compound, berkleasmin A (3) (Figure 1). ${ }^{10}$ In this paper, the taxonomy of the producing strain, isolation, physicochemical properties and structure elucidation of $\mathbf{1}$ and 2, as well as circumvention activities of ABK resistance of the isolated compounds, are described.

\section{RESULTS}

Taxonomy of the producing strain TR-022

The fungal strain TR-022 was isolated from a sediment collected in an artificial pond at Machida city, Tokyo. As TR-022 did not produce spores on agar media, molecular identification was carried out. A BLAST search of partial sequences of large subunit and internal transcribed spacer region (ITS) revealed that TR-022 possessed the highest sequence similarities with Paraconiothyrium brasiliense CBS 122851 (99.7\%) and Paraphaeosphaeria sporulosa CBS 824.68 (96.8\%), respectively. The phylogenetic tree based on ITS sequences clearly indicated that TR-022 was nested in a ParaphaeosphaeriaParaconiothyrium clade ${ }^{11}$ and did not cluster with any species within a clade (Figure 2). Thus, TR-022 was designated as a Paraphaeosphaeria sp.

\section{Isolation}

The $80 \%$ isopropanol extract (4.5l) was evaporated under reduced pressure to remove isopropanol. The aqueous solution (11) was extracted twice with 11 of ethyl acetate. The organic layer was concentrated to dryness in vacuo to afford a crude material $(11.8 \mathrm{~g}$ ) and applied to a silica gel column (60 i.d. $\times 100 \mathrm{~mm})$, which was

\footnotetext{
${ }^{1}$ Department of Drug Discovery Sciences, Graduate School of Infection Control Sciences, Kitasato University, Tokyo, Japan; ${ }^{2}$ Kitasato Institute for Life Sciences, Kitasato University, Tokyo, Japan and ${ }^{3}$ Chemical Research Laboratories, Kyowa Hakko Kirin, Co., Ltd., Shizuoka, Japan

Correspondence: Professor K Shiomi or Professor S Ōmura, Kitasato Institute for Life Sciences, Kitasato University, 5-9-1 Shirokane, Minato-ku, Tokyo 108-8641, Japan. E-mail: shiomi@lisci.kitasato-u.ac.jp or omuras@insti.kitasato-u.ac.jp

This article is dedicated to the fond memory of the late Professor Lester Mitscher, a great scholar, teacher and Emeritus Editor of this Journal.

Received 29 March 2016; revised 13 April 2016; accepted 9 May 2016; published online 22 June 2016
} 
<smiles>C=C1C(=O)N(OC)C(=O)C2=C1O[C@H](CCCCCCC)C(C)(O)C2O</smiles>

Paraphaeosphaeride D (1)

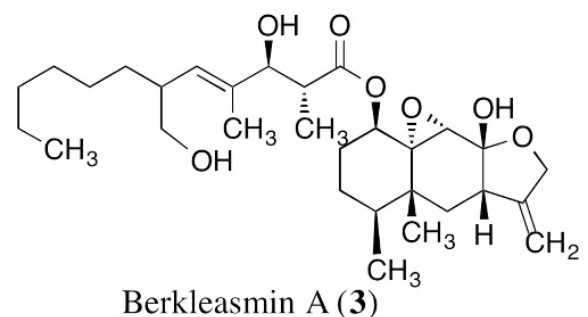

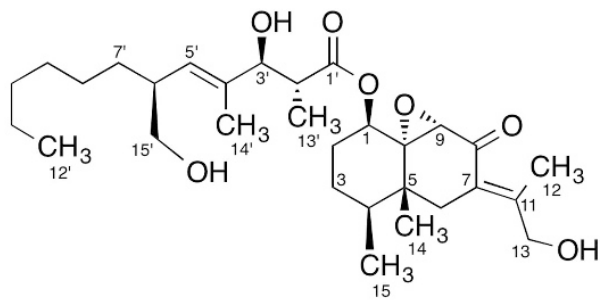

Berkleasmin F (2)

Figure 1 Structures of paraphaeosphaeride D (1), berkleasmin F (2) and berkleasmin A (3).

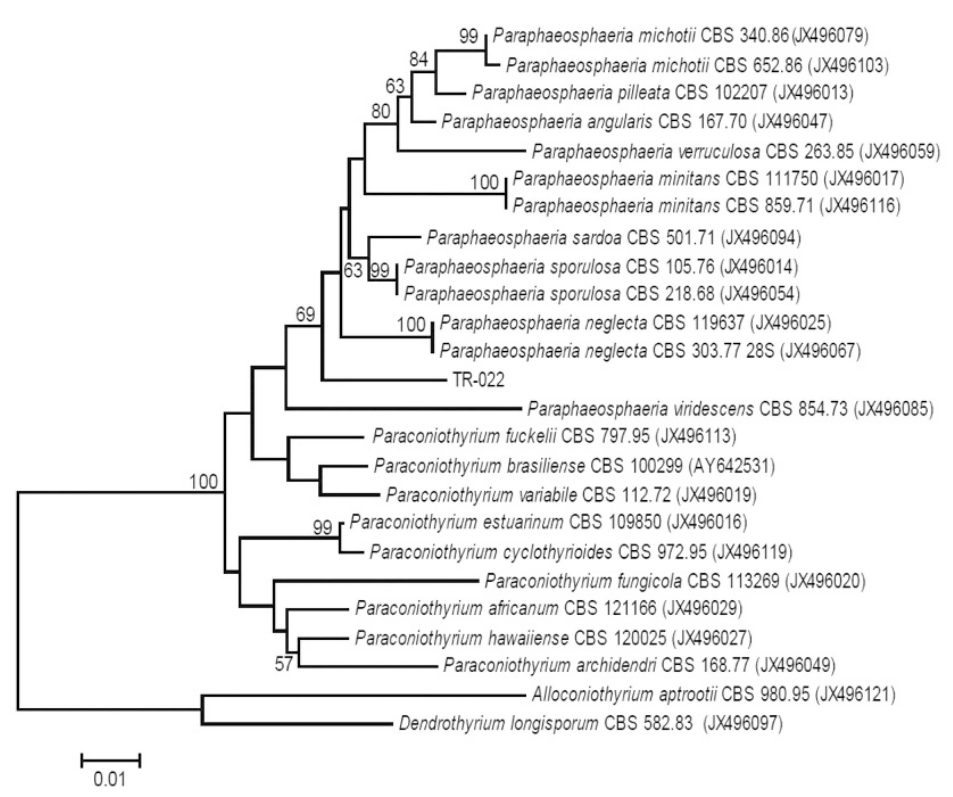

Paraphaeosphaeria

/Paraconiothyrium

Figure 2 The neighbor-joining tree based on internal transcribed spacer region sequences showing the relationships between TR-022 and Paraphaeosphaerial Paraconiothyrium species. The numbers at branch are bootstrap values as a percentage of 1000 replications (only values above $50 \%$ are shown). Scale bar $=0.01$ substitutions per site.

eluted stepwise with 11 each of a mixture of $\mathrm{CHCl}_{3}-\mathrm{MeOH}$ (100:0, $100: 2,100: 5,100: 7,10: 1,1: 1$ and $0: 100)$ in this order. The $\mathrm{CHCl}_{3}-\mathrm{MeOH}$ (100:5) fraction (4.1 g) was applied on an octadecylsilyl column $(60$ i.d. $\times 50 \mathrm{~mm}$ ), which was eluted stepwise with $20,50,60$, 70, 80, 90 and $100 \%$ of $\mathrm{MeOH} / \mathrm{H}_{2} \mathrm{O}$ solvents (each $500 \mathrm{ml}$ ). One gram of the active fraction $(80 \% \mathrm{MeOH}$ aq. fraction, $1.1 \mathrm{~g})$ was dissolved in a small amount of $\mathrm{MeOH}$ and was applied in 10 aliquots to a preparative HPLC (Capcell pak C18 UG-120, 20 i.d. $\times 250 \mathrm{~mm}$, Shiseido Co., Tokyo, Japan) with $80 \%$ of $\mathrm{MeOH} / \mathrm{H}_{2} \mathrm{O}$ solvent (flow

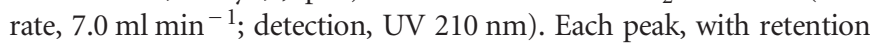
times of 14, 28 and $36 \mathrm{~min}$, was collected and concentrated in vacuo to dryness to afford paraphaeosphaeride D $(1,34.4 \mathrm{mg})$, berkleasmin $\mathrm{F}(2,62.9 \mathrm{mg})$ and a known compound, berkleasmin $\mathrm{A}(3,581 \mathrm{mg})$, respectively.
Structure elucidation of paraphaeosphaeride D (1)

Compound 1 was obtained as a yellow oil $\left([\alpha]_{\mathrm{D}}{ }^{27}-6 ; c=0.1, \mathrm{MeOH}\right)$, readily soluble in $\mathrm{CHCl}_{3}$ and $\mathrm{MeOH}$. It showed UV absorption maxima at $265 \mathrm{~nm}(\mathrm{sh}, \varepsilon 2470)$ and $226 \mathrm{~nm}(\varepsilon 7900)$ in $\mathrm{MeOH}$. The IR absorption at 1666 and $3355 \mathrm{~cm}^{-1}$ indicated the presence of ketone and hydroxy groups. The molecular formula of $\mathbf{1}$ was elucidated by HR-ESI-MS to be $\mathrm{C}_{17} \mathrm{H}_{27} \mathrm{NO}_{5}$ (found $\mathrm{m} / z 348.1792[\mathrm{M}+\mathrm{Na}]^{+}$, calcd. $\mathrm{m} / \mathrm{z}$ 348.1787), requiring five degrees of unsaturation. The ${ }^{1} \mathrm{H}$ and ${ }^{13} \mathrm{C}$ NMR spectra data of 1 is listed in Table 1 . The ${ }^{13} \mathrm{C}$ NMR and HSQC spectra indicated 17 carbons, which were classified into four $s p^{2}$ fully substituted carbons, including one carbonyl carbon, two oxygenated $s p^{3}$ methines, one oxygenated $s p^{3}$ fully substituted carbon, one $s p^{2}$ exomethylene, six methylenes and three methyls, including one methoxy group. The ${ }^{1} \mathrm{H}_{-}{ }^{1} \mathrm{H}$ COSY of $\mathbf{1}$ indicated the assignments 
Table $1{ }^{1} \mathrm{H}$ and ${ }^{13} \mathrm{C}$ NMR spectral data of paraphaeosphaeride D (1) in $\mathrm{CDCl}_{3}$

\begin{tabular}{|c|c|c|c|c|}
\hline \multirow{3}{*}{$\frac{\text { No. }}{1}$} & \multicolumn{4}{|c|}{ Paraphaeosphaeride D (1) } \\
\hline & \multicolumn{2}{|c|}{$\delta_{C}$ mult. } & \multicolumn{2}{|c|}{$\delta_{H}$ mult. $(\mathrm{J}$ in $\mathrm{Hz})$} \\
\hline & 166.5 & C & & \\
\hline 3 & 136.3 & C & & \\
\hline 4 & 156.1 & C & & \\
\hline 5 & 104.3 & C & & \\
\hline 6 & 68.1 & $\mathrm{CH}$ & 4.46 & $\mathrm{~s}$ \\
\hline 7 & 71.7 & C & & \\
\hline 8 & 86.2 & $\mathrm{CH}$ & 4.04 & $t(6.8)$ \\
\hline 9 & 27.5 & $\mathrm{CH}_{2}$ & 1.79 & $\mathrm{~m}$ \\
\hline 10 & 26.5 & $\mathrm{CH}_{2}$ & $\begin{array}{c}1.27-1.34^{\mathrm{a}} \\
1.57\end{array}$ & $\begin{array}{l}\mathrm{m} \\
\mathrm{m}\end{array}$ \\
\hline 11 & $29.2^{b}$ & $\mathrm{CH}_{2}$ & $1.27-1.34^{a}$ & $\mathrm{~m}$ \\
\hline 12 & $29.3^{b}$ & $\mathrm{CH}_{2}$ & $1.27-1.34^{a}$ & m \\
\hline 13 & 31.8 & $\mathrm{CH}_{2}$ & $1.27-1.34^{\mathrm{a}}$ & $\mathrm{m}$ \\
\hline 14 & 22.6 & $\mathrm{CH}_{2}$ & $1.27-1.34^{\mathrm{a}}$ & $\mathrm{m}$ \\
\hline 15 & 14.1 & $\mathrm{CH}_{3}$ & 0.88 & $\mathrm{t}(7.2)$ \\
\hline 16 & 92.6 & $\mathrm{CH}_{2}$ & $\begin{array}{l}5.03 \\
5.08\end{array}$ & $\begin{array}{l}d(1.6) \\
d(1.6)\end{array}$ \\
\hline 17 & 16.8 & $\mathrm{CH}_{3}$ & $1.27^{\mathrm{a}}$ & $\mathrm{s}$ \\
\hline 18 & 64.5 & $\mathrm{CH}_{3}$ & 3.90 & $\mathrm{~s}$ \\
\hline
\end{tabular}

Abbreviation: mult., multiplicity.

NMR spectra were recorded at $400 \mathrm{MHz}$ for ${ }^{1} \mathrm{H}$ and $125 \mathrm{MHz}$ for ${ }^{13} \mathrm{C}$

averlapped.

Exchangable.

from $\mathrm{H}-8$ to $\mathrm{H}_{2}-10$ and from $\mathrm{H}_{3}-15$ to $\mathrm{H}_{2}-14$ (Figure $3 \mathrm{a}$ ). The HMBC correlations from $\mathrm{H}_{3}-17\left(\delta_{\mathrm{H}} 1.27\right)$ to $\mathrm{C}-6\left(\delta_{\mathrm{C}} 68.1\right), \mathrm{C}-7\left(\delta_{\mathrm{C}} 71.7\right)$ and C-8 $\left(\delta_{\mathrm{C}} 86.2\right)$, from H-6 $\left(\delta_{\mathrm{H}} 4.46\right)$ to C-7, C-8 and C-17 $\left(\delta_{\mathrm{C}} 16.8\right)$, from $\mathrm{H}-8\left(\delta_{\mathrm{H}} 4.04\right)$ to $\mathrm{C}-6, \mathrm{C}-7$ and $\mathrm{C}-17$ established the connectivity between C- 6 and C-8 and attachment of C-17 to C-7. The presence of 3,4-dihyroxy-3-methyl-3,4-dihydro- $2 \mathrm{H}$-pyran ring was suggested by the HMBC correlations from $\mathrm{H}-6$ to $\mathrm{C}-5\left(\delta_{\mathrm{C}} 104.3\right)$ and C-4 and from $\mathrm{H}-8$ to $\mathrm{C}-4$, and the ${ }^{13} \mathrm{C}$ chemical shifts of C-4 $\left(\delta_{\mathrm{C}} 156.1\right)$. HMBC and COSY correlations suggested that this pyran ring was connected to a $n$-heptyl side chain at C- 8 position, as shown in Figure $3 \mathrm{a}$. The exomethylene protons $\left(\delta_{\mathrm{H}} 5.03\right.$ and 5.08, $\left.\mathrm{H}_{2}-16\right)$ showed HMBC correlations to carbons at C- 4 and $\mathrm{C}-3\left(\delta_{\mathrm{C}} 136.3\right)$, which indicated C-3 was located between C-16 and C-4. One singlet methyl, one carbonyl group and one atom each of nitrogen and oxygen remain from the molecular formula. The remaining methyl group is very highly deshielded, with ${ }^{13} \mathrm{C}$ chemical shift of $\delta_{\mathrm{C}} 64.5$ and ${ }^{1} \mathrm{H}$ chemical shift of $\delta_{\mathrm{H}} 3.90\left(\mathrm{H}_{3}-18\right)$, and hence it must be attached to oxygen. The HMBC correlation from H-6 to C-1 $\left(\delta_{\mathrm{H}}\right.$ 166.5) and remaining one unsaturation degree indicated connectivity between C-1 and C-3 via a nitrogen atom, substituted with a methoxy group, to form a $N$-methoxy- $\gamma$-methylidene- $\alpha, \beta$-unsaturated- $\gamma$-lactam ring. This unique moiety was confirmed by the comparison of ${ }^{1} \mathrm{H}$ and ${ }^{13} \mathrm{C}$ chemical shifts between $\mathbf{1}$ and phaeosphaeride $\mathrm{A},{ }^{16}$ and we consequently designated $\mathbf{1}$ as paraphaeosphaeride D.
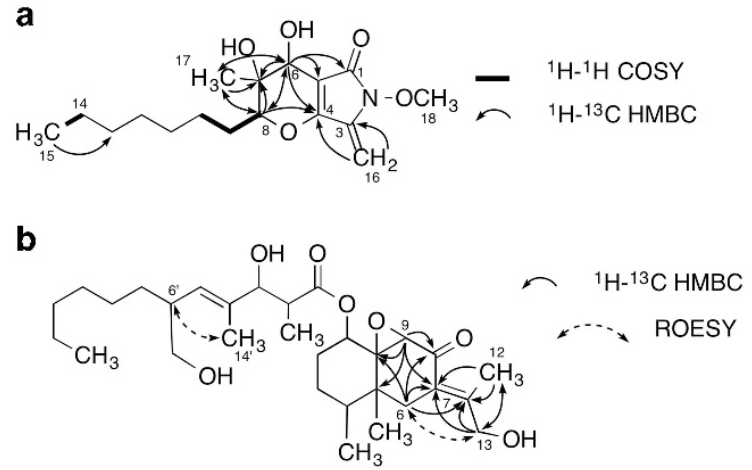

C

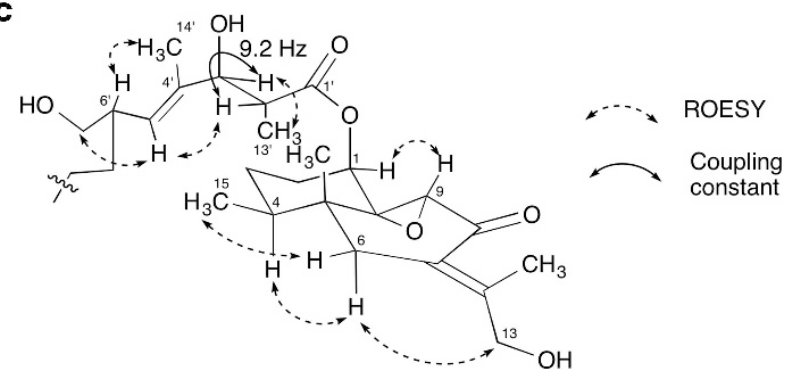

Figure 3 (a) COSY and key HMBC correlations of paraphaeosphaeride D (1). (b) Key HMBC and key ROESY correlations of berkleasmin F (2). (c) ROESY correlations and coupling constants of berkleasmin $F(2)$.

Structure elucidation of berkleasmin F (2)

Compound 2 was obtained as a yellow oil $\left([\alpha]_{\mathrm{D}}^{27} 0.4 ; c=0.1, \mathrm{MeOH}\right)$, soluble in $\mathrm{CHCl}_{3}$ and $\mathrm{MeOH}$. It showed UV absorption maxima at $203 \mathrm{~nm}(\varepsilon 5800)$ and $273 \mathrm{~nm}(\varepsilon$ 3300) in MeOH. The IR absorption at $1720 \mathrm{~cm}^{-1}$ and $3401 \mathrm{~cm}^{-1}$ of 2 suggested the presence of ketone and hydroxy groups. The similarity in physicochemical properties between 2 and the known 3 strongly suggested that 2 is a new analog of $3^{10}$. The molecular formula of 2 was elucidated by HR-ESI-MS to be $\mathrm{C}_{30} \mathrm{H}_{48} \mathrm{O}_{7}$ (found $\mathrm{m} / z$ 543.3285 $[\mathrm{M}+\mathrm{Na}]^{+}$, calcd. $\mathrm{m} / \mathrm{z}$ 543.3298), indicating that 2 had the same molecular formula as that of 3 . The ${ }^{1} \mathrm{H}$ and ${ }^{13} \mathrm{C}$ NMR spectra data of 2 is listed in Table 2. NMR spectra of 2 lacked a tetrahydrofuran ring and the exomethylene of 3 and had new signals of a ketone $\left(\delta_{\mathrm{C}} 197.3\right)$, an oxymethylene $\left(\delta_{\mathrm{H}} 4.10\right.$ and $\left.4.29, \delta_{\mathrm{C}} 63.6\right)$, two fully substituted olefinic carbons $\left(\delta_{\mathrm{C}} 127.6\right.$ and $150.6)$ and an olefinic methyl group $\left(\delta_{\mathrm{H}} 2.16, \delta_{\mathrm{C}} 31.0\right)$. The HMBC experiments (Figure $3 \mathrm{~b}$ ) gave the following results; the proposed sesquiterpene core structure was confirmed by the key HMBC correlations: from $\mathrm{H}-9\left(\delta_{\mathrm{H}} 3.44\right)$ to $\mathrm{C}-5\left(\delta_{\mathrm{C}} 36.9\right), \mathrm{C}-7\left(\delta_{\mathrm{C}} 127.6\right)$, C-8 $\left(\delta_{\mathrm{C}} 197.3\right)$ and $\mathrm{C}-10\left(\delta_{\mathrm{C}} 68.0\right)$, from $\mathrm{H}_{2}-6\left(\delta_{\mathrm{H}} 2.33\right.$ and 2.37$)$ to C-7, C-8, C-10 and C-11 ( $\left.\delta_{C} 150.6\right)$, from $\mathrm{H}_{3}-12\left(\delta_{\mathrm{H}} 2.16\right)$ to $\mathrm{C}-7$, $\mathrm{C}-11$ and $\mathrm{C}-13\left(\delta_{\mathrm{C}} 63.6\right)$ and from $\mathrm{H}_{2}-13\left(\delta_{\mathrm{H}} 4.10\right)$ to $\mathrm{C}-7, \mathrm{C}-11$ and $\mathrm{C}-12$ to form 1-hydroxy-2-propylidene group at C-7 position. The chemical shifts of the side chain (from C-1' to C-15') is almost the same as those of 3 . The ROESY correlation (Figure 3b), observed between $\mathrm{H}-6$ and $\mathrm{H}-13$ and between $\mathrm{H}_{3}-14^{\prime}$ and $\mathrm{H}-6^{\prime}$, were elucidated to be $7 E$ and $4^{\prime} E$. The ${ }^{1} \mathrm{H}$ and ${ }^{13} \mathrm{C}$ chemical shifts of an allylic methyl group $\left(\delta_{\mathrm{H}} 2.16, \delta_{\mathrm{C}} 31.0\right)$ were shifted downfield by the anisotropic effect of the carbonyl group at C-8. Therefore, the planar structure of $\mathbf{2}$ was elucidated as shown in Figure $3 \mathrm{~b}$ and we designated 2 to be berkleasmin F.

The relative configuration of $\mathbf{2}$ was elucidated by the analysis of ROESY and the coupling constants. The $\beta$-oriented configuration of $\mathrm{H}_{3}-15$, and $\mathrm{H}-9$ and the $\alpha$-oriented configuration of $\mathrm{H}-1$ were 
Table $2{ }^{1} \mathrm{H}$ and ${ }^{13} \mathrm{C}$ NMR spectral data of berkleasmin $\mathrm{F}(2)$ in $\mathrm{CDCl}_{3}$

\begin{tabular}{|c|c|c|c|c|}
\hline \multirow{3}{*}{$\frac{\text { No. }}{1}$} & \multicolumn{4}{|c|}{ Berkleasmin F (2) } \\
\hline & \multicolumn{2}{|c|}{$\delta_{C}$ mult. } & \multicolumn{2}{|c|}{$\delta_{H}$ mult. $(\mathrm{J}$ in $\mathrm{Hz})$} \\
\hline & 74.4 & $\mathrm{CH}$ & 4.56 & $\mathrm{t}(2.8)$ \\
\hline 2 & 29.2 & $\mathrm{CH}_{2}$ & 1.90 & $\mathrm{~m}$ \\
\hline 3 & 25.4 & $\mathrm{CH}_{2}$ & $\begin{array}{l}1.47 \\
1.70\end{array}$ & $\begin{array}{l}\mathrm{m} \\
\mathrm{m}\end{array}$ \\
\hline 4 & 39.5 & $\mathrm{CH}$ & 1.71 & $\mathrm{~m}$ \\
\hline 5 & 36.9 & C & & \\
\hline 6 & 36.8 & $\mathrm{CH}_{2}$ & $\begin{array}{l}2.33 \\
2.37\end{array}$ & $\begin{array}{l}d(15.4) \\
d(15.4)\end{array}$ \\
\hline 7 & 127.6 & C & & \\
\hline 8 & 197.3 & $\mathrm{C}$ & & \\
\hline 9 & 62.6 & $\mathrm{CH}$ & 3.44 & $\mathrm{~s}$ \\
\hline 10 & 68.0 & $\mathrm{C}$ & & \\
\hline 11 & 150.6 & C & & \\
\hline 12 & 31.0 & $\mathrm{CH}_{3}$ & 2.16 & s \\
\hline 13 & 63.6 & $\mathrm{CH}_{2}$ & $\begin{array}{l}4.10 \\
4.29\end{array}$ & $\begin{array}{l}d(14.2) \\
d(14.2)\end{array}$ \\
\hline 14 & 17.7 & $\mathrm{CH}_{3}$ & 1.04 & $\mathrm{~s}$ \\
\hline 15 & 16.5 & $\mathrm{CH}_{3}$ & 0.96 & s \\
\hline $1^{\prime}$ & 174.4 & C & & \\
\hline $2^{\prime}$ & 43.3 & $\mathrm{CH}$ & 2.63 & $\mathrm{dq}(9.2,6.9)$ \\
\hline $3^{\prime}$ & 80.4 & $\mathrm{CH}$ & 4.09 & $d(9.2)$ \\
\hline $4^{\prime}$ & 137.1 & $\mathrm{C}$ & & \\
\hline $5^{\prime}$ & 131.8 & $\mathrm{CH}$ & 5.15 & $d(10.0)$ \\
\hline $6^{\prime}$ & 40.8 & $\mathrm{CH}$ & 2.54 & $\mathrm{~m}$ \\
\hline $7^{\prime}$ & 31.4 & $\mathrm{CH}_{2}$ & $1.21-1.29^{\mathrm{a}}$ & $\mathrm{m}$ \\
\hline $8^{\prime}$ & 27.2 & $\mathrm{CH}_{2}$ & $1.21-1.29^{\mathrm{a}}$ & $\mathrm{m}$ \\
\hline $9^{\prime}$ & 29.2 & $\mathrm{CH}_{2}$ & $1.21-1.29^{\mathrm{a}}$ & $\mathrm{m}$ \\
\hline $10^{\prime}$ & 31.8 & $\mathrm{CH}_{2}$ & $1.21-1.29^{a}$ & $\mathrm{~m}$ \\
\hline $11^{\prime}$ & 22.6 & $\mathrm{CH}_{3}$ & $1.21-1.29^{a}$ & $\mathrm{~m}$ \\
\hline $12^{\prime}$ & 14.0 & $\mathrm{CH}_{3}$ & 0.86 & $\mathrm{t}(7.2)$ \\
\hline $13^{\prime}$ & 14.2 & $\mathrm{CH}_{3}$ & 1.03 & $d(6.9)$ \\
\hline $14^{\prime}$ & 11.2 & $\mathrm{CH}_{3}$ & 1.62 & $\mathrm{~s}$ \\
\hline $15^{\prime}$ & 66.5 & $\mathrm{CH}_{2}$ & $\begin{array}{l}3.36 \\
3.57\end{array}$ & $\begin{array}{l}\mathrm{m} \\
\mathrm{m}\end{array}$ \\
\hline
\end{tabular}

Abbreviation: mult., multiplicity.

NMR spectra were recorded at $400 \mathrm{MHz}$ for ${ }^{1} \mathrm{H}$ and $125 \mathrm{MHz}$ for ${ }^{13} \mathrm{C}$.

aOverlapped.

deduced by ROESY correlations between $\mathrm{H}_{3}-15$ and $\mathrm{H}-6 \beta\left(\delta_{\mathrm{H}} 2.33\right)$, between $\mathrm{H}-4$ and $\mathrm{H}-6 \alpha\left(\delta_{\mathrm{H}} 2.37\right)$, between $\mathrm{H}-6 \alpha$ and $\mathrm{H}_{2}-13\left(\delta_{\mathrm{H}} 4.29\right)$ and between $\mathrm{H}-1$ and $\mathrm{H}-9$ (Figure $3 \mathrm{c}$ ). The same relative configuration of C-2', C-3' and C- $6^{\prime}$ on the acyl side chain of 2 was elucidated to be the same as those of berkleasmins A-E, evidenced by a large coupling constant $(9.2 \mathrm{~Hz})$ between $\mathrm{H}-2^{\prime}$ and $\mathrm{H}-3^{\prime}$ and ROESY correlations between $\mathrm{H}_{3}-13^{\prime}$ and $\mathrm{H}-3^{\prime}$, between $\mathrm{H}-2^{\prime}$ and $\mathrm{H}-5^{\prime}$, between $\mathrm{H}_{3}-14^{\prime}$ and $\mathrm{H}-6^{\prime}$ and between $\mathrm{H}-5^{\prime}$ and $\mathrm{H}_{2}-15^{\prime}$. Thus the relative configuration of 2 was elucidated to be $1 R^{\star}, 4 S^{\star}, 5 R^{\star}, 9 S^{\star}, 10 R^{\star}, 2^{\prime} R^{\star}, 3^{\prime} S^{\star}, 6^{\prime} S^{\star}$.

\section{Activity of 1, 2 and 3 against ABK resistance in MRSA}

The activity of 1, 2 and $\mathbf{3}$ with respect to overcoming ABK resistance in MRSA was evaluated against the ABK-resistant TH-1466 strain using the paper disc method (Table 3). All compounds enhanced anti-MRSA activity, with the effectiveness of ABK being improved 10-, 30- and 100-fold for 1, 2 and 3, respectively.

The compounds were also tested against the TH-1466 strain using the agar dilution assay. The MIC values of 1, 2 and 3 were 256, 16 and $16 \mu \mathrm{g} \mathrm{ml}^{-1}$, respectively.
Table 3 Circumvention of ABK resistance in MRSA TH-1466 using the paper disc method

\begin{tabular}{|c|c|c|c|c|c|c|}
\hline \multirow[b]{3}{*}{$\mu g$ per disc } & \multicolumn{6}{|c|}{ Inhibition zone $(\mathrm{mm}) / 6 \mathrm{~mm}$ disc } \\
\hline & \multicolumn{2}{|c|}{1} & \multicolumn{2}{|c|}{2} & \multicolumn{2}{|c|}{3} \\
\hline & $A B K(+)$ & $A B K(-)$ & $A B K(+)$ & $A B K(-)$ & $A B K(+)$ & $A B K(-)$ \\
\hline 100.0 & 20 & 12 & 14 & 8 & NT & NT \\
\hline 30.0 & 16 & 7 & 12 & - & 20 & 11 \\
\hline 10.0 & 12 & - & 10 & - & 17 & 8 \\
\hline 3.0 & 8 & - & 8 & - & 13 & - \\
\hline 1.0 & - & - & 7 & - & 14 & - \\
\hline 0.3 & - & - & - & - & 11 & - \\
\hline 0.1 & NT & NT & - & - & - & - \\
\hline
\end{tabular}

A population analysis was subsequently undertaken of the impact of the compounds on anti-MRSA activity against 26 clinical isolated strains harboring the gene of aminoglycoside-modifying enzyme aac $\left(6^{\prime}\right)$-Ielaph(2' $2^{\prime \prime}$-Ia (Table 4). Compounds 1, 2 and 3 showed antiMRSA activity, with MIC values ranging from 128 to $>256 \mu \mathrm{g} \mathrm{ml}^{-1}$, $16 \mu \mathrm{g} / \mathrm{ml}$ and from 8 to $16 \mu \mathrm{g} \mathrm{ml}^{-1}$, respectively. The circumvention impact of 1, 2 and 3 against 26 clinical isolated strains was 1- to 16-fold, and it was similar to the impact against TH-1466 strain (4-fold).

The inhibitory activity against the bifunctional enzyme AAC(6')-Ie/ $\mathrm{APH}\left(2^{\prime \prime}\right)-\mathrm{Ia}$ was also evaluated using a cloned recombinant enzyme from the MRSA TH-1466 strain. ${ }^{8}$ Surprisingly, all three compounds failed to inhibit phosphorylation and acetylation, even at $1 \mathrm{mg} \mathrm{ml}^{-1}$ (data not shown).

\section{DISCUSSION}

We found $\mathbf{1}$ and 2, isolated from the culture broth of Paraphaeosphaeria sp. TR-022, to be circumventors of ABK resistance in MRSA, similar to the known compoyund 3. It is interesting that the microorganism simultaneously produces metabolites with a variety of different skeletal structures. Especially, 1 has an unusual skeleton containing a 3-pyrrolin-2-one moiety, which has been reported previously in seven compounds. ${ }^{12-14}$ Very recently, biosynthetic pathways of pyranonigrins, which have skeleton similar to 1 , have been reported, ${ }^{15}$ in which the polyketide synthase-non-ribosomal peptide synthetase (PKS-NRPS) hybrid enzyme was proposed to form a precursor of pyraonigrin E using one acetyl-CoA, six malonyl-CoAs and one L-serine as substrates. Phaeosohaerides were reported to inhibit the signal transducer and activate the transcription 3 (STAT3) pathway, acting as anti-tumor reagents, but the action mechanisms are poorly understood. However, other biological activities of the phaeosphaerides have not been reported. Compound 2 has an eremophilane sesquiterpenoid skeleton similar to that of 3. Many eremophilane-type compounds possess unique chemical structures and a variety of bioactivities. ${ }^{16,17}$ Compounds 2 and 3 showed ABK circumvention activity against MRSA.

Both 1 and 2 reduced the MIC values of ABK against MRSA, from $16 \mu \mathrm{g} \mathrm{ml}^{-1}$ to $4 \mu \mathrm{g} \mathrm{ml}^{-1}$ (fourfold), but they did not inhibit the bifunctional enzyme $\mathrm{AAC}\left(6^{\prime}\right)-\mathrm{Ie} / \mathrm{APH}\left(2^{\prime \prime}\right)-\mathrm{Ia}$, even at $1 \mathrm{mg} \mathrm{ml}^{-1}$. These results indicate that they might have another mechanism for lowering drug resistance. Such inhibition mechanisms remain poorly defined or understood. ABK uptake may be modified by changing membrane permeability and energy metabolism in MRSA, due to 
Table 4 Circumvention of ABK resistance in MRSA TH-1466 and 26 clinical isolate strains using the agar dilution method

\begin{tabular}{|c|c|c|c|c|c|c|}
\hline & \multicolumn{3}{|c|}{$M I C\left(\mu g m l^{-1}\right)$} & \multicolumn{3}{|c|}{ Cirucumvention activity by combination assay ${ }^{a}$ (times) } \\
\hline & \multicolumn{3}{|c|}{26 clinical isolates } & \multicolumn{3}{|c|}{26 clinical isolates } \\
\hline & TH-1466 & Average & Range $^{\mathrm{b}}$ & TH-1466 & Average & Range \\
\hline ABK & 16 & 15.7 & $8-32$ & & & \\
\hline 1 & 256 & 187 & $128->256$ & 4 & 6.2 & $2-16$ \\
\hline 2 & 16 & 16.0 & 16 & 4 & 3.0 & $1-8$ \\
\hline 3 & 16 & 15.7 & $8-16$ & 4 & 2.8 & $1-4$ \\
\hline
\end{tabular}

Abbreviations: ABK, arbekacin; MRSA, methicillin-resistant Staphylococcus aureus.

aConcentrations of the compounds (1-3) were used $1 / 4$ MIC values.

Compounds were evaluated against 26 clinical isolated strains.

effects such as the proton motive force. ${ }^{18,19}$ We identified $\mathbf{1}$ and $\mathbf{2}$ as new chemicals that might prove to be promising lead compounds for developing circumventors of ABK resistance in MRSA.

\section{METHODS}

\section{Taxonomic study}

For molecular identification of TR-022, a nuclear ribosomal large subunit and ITS were analyzed. Primers of ITS5 (5'-GGAAGTAAAAGTCGTAACAAGG-3') and NL4 (5'-GGTCCGTGTTTCAAGACGG-3') were used for PCR amplification. The PCR product was sequenced using primers of ITS5, ITS4 (5'-T CCTCCGCTTATTGATATGC-3')， NL1 (5'-GCATATCAATAAGCGGAGGA AAAG-3') and NL4. The determined DNA sequences were deposited to the DNA Data Bank of Japan as accession number LC115035. BLAST searches were performed to compare large subunit and ITS sequences of TR-022 with DNA sequences in public databases. The ITS sequence of TR-022 was aligned with those of 24 fungal strains selected based on the BLAST result as well as on taxonomical references. ${ }^{11,20}$ The phylogenetic tree was constructed by MEGA ver. $6.0 .^{21}$

\section{Fermentation}

A piece of TR-022 grown on agar was inoculated into $10 \mathrm{ml}$ seed medium [mashed potato (Megmilk Snow Brand Co., Ltd., Tokyo, Japan) 3\%, glucose $2 \%$, yeast extract $0.5 \%,(\mathrm{pH} 6.0)$ in a test tube and shaken for 5 days ( 280 r.p.m. at $25^{\circ} \mathrm{C}$ ). Five $\mathrm{ml}$ of the seed culture was inoculated into $45 \mathrm{ml}$ of the same medium in each of 11 Erlenmeyer flasks and cultured for 2 days (200 r.p.m. at $25^{\circ} \mathrm{C}$ ). The mixed culture $(24 \mathrm{ml})$ was seeded onto fermentation medium (oat meal (Tomizawa Shouten Inc., Tokyo, Japan) $70 \mathrm{~g}$, soybean meal (J-Oil Mills, Inc., Tokyo, Japan) $7 \mathrm{~g}, 140 \mathrm{ml}$ distilled water) in 20 polypropylene containers and left standing for 12 days at $25^{\circ} \mathrm{C}$.

\section{General experiments}

NMR spectra were measured by a Varian XL-400 spectrometer (Agilent Technologies, CA, USA), with ${ }^{1} \mathrm{H}$ NMR at $400 \mathrm{MHz}$ and ${ }^{13} \mathrm{C}$ NMR at $100 \mathrm{MHz}$ in $\mathrm{CDCl}_{3}$. The chemical shifts are expressed in p.p.m. and are referred to $\mathrm{CHCl}_{3}$ (7.26 p.p.m.) in the ${ }^{1} \mathrm{H}$ NMR spectra and to $\mathrm{CDCl}_{3}$ (77.0 p.p.m.) in the ${ }^{13} \mathrm{C}$ NMR spectra. ESI-MS spectra were measured with a JMS AX-505 HA mass spectrometer (JEOL Ltd., Tokyo, Japan). IR spectra (ATR) were observed using a FT-210 Fourier transform IR spectrometer (Horiba Ltd., Kyoto, Japan). UV spectra were measured with a Hitachi U-2801 spectrophotometer (Hitachi Ltd., Tokyo, Japan). Optical rotation was measured with a JASCO P-2200 polarimeter (JASCO Corporation, Tokyo, Japan).

\section{Assay for circumvention of $\mathrm{ABK}$ resistance in MRSA}

Using an MRSA TH-1466 strain, a clinical ABK-resistant isolate harboring the gene for the aminoglycoside-modifying enzyme aac (6')-Ie/aph( $\left.2^{\prime \prime}\right)-I a$, circumvention of ABK resistance in MRSA was evaluated by the paper disc method and the agar dilution method. The paper disc method was carried out according to the following protocol; the MRSA was cultured in $4 \mathrm{ml}$ of Difco Mueller Hinton broth (MHB; Becton Dickinson, NJ, USA) at $37^{\circ} \mathrm{C}$ for
20 hours and adjusted to $1 \times 10^{8} \mathrm{CFU}$ per $\mathrm{ml}$. Seven hundred and fifty microliters of the culture broth was transferred to a square plate $(10 \times 14 \mathrm{~cm}$, Eiken Chemical Co., Ltd., Tokyo, Japan) containing $20 \mathrm{ml}$ of Difco Mueller Hinton agar (MHA; Becton Dickinson), with or without ABK $\left(8 \mu \mathrm{g} \mathrm{ml} l^{-1}\right.$, Meiji Seika Pharma Co., Ltd., Tokyo, Japan) whose concentration has no effect on the growth of MRSA. Paper disks (6 mm, Advantec Toyo Kaisha, Ltd., Tokyo, Japan) containing various amounts of a sample (or $7 \mu \mathrm{g}$ per disc of vancomycin as a positive control) were placed on the MHA plate and incubated at $37^{\circ} \mathrm{C}$ overnight. Anti-MRSA activity was expressed as the diameter (mm) of the inhibition zone.

The agar dilution assay was carried out according to the method recommended by NCCLS. ${ }^{22}$ Population analysis of the MIC value of ABK together with 1-3 was studied against 26 clinical isolated MRSA. ${ }^{23}$ Concentrations of the 1/4 MIC values of 1-3 were used for the combination assay.

\section{CONFLICT OF INTEREST}

The authors declare no conflict of interest.

\section{ACKNOWLEDGEMENTS}

This study was supported, in part, by funds from Quality Assurance Framework of Higher Education from the Ministry of Education, Culture, Sports, Science and Technology in Japan (MEXT) and by Grant-in-Aid for Scientific Research (C, 21580129) to KS from the Japan Society for the Promotion of Science. We would like to thank Dr Kenichiro Nagai and Ms Noriko Sato, School of Pharmacy, Kitasato University for measurements of mass and NMR spectra.

1 Saga, T. \& Yamaguchi, K. History of antimicrobial agents and resistant bacteria. Jpn. Med. Assoc. J. 52, 103-108 (2009).

2 Kondo, S., linuma, K., Yamamoto, H., Maeda, K. \& Umezawa, H. Syntheses of $1-N$ - $\left\{(S)\right.$-4-amino-2hydroxybutyry\}-kanamycin B and $-3^{\prime}, 4^{\prime}$-dideoxykanamycin B and -3',4'-dideoxykanamycin B active against kanamycin-resistant bacteria. J. Antibiot. 26, 412-415 (1973).

3 Kondo, S. et al. New 2"-amino derivatives of arbekacin, potent aminoglycoside antibiotics against methicillin-resistant Staphylococcus aureus. J. Antibiot. 46, 531-533 (1993).

4 Mikuniya, T. et al. Prevalence of drug resistant gene and changes in susceptibility of methicillin-resistant Staphylococcus aureus strains isolated from 1990 to 2006 in Japan to antimicrobial agents. Jpn. J. Chemother. 57, 37-40 (2009).

5 Kondo, S. Development of arbekacin and synthesis of new derivatives stable to enzymatic modifications by methicillin-resistant Staphylococcus aureus. Jpn J. Antibiot. 47, 561-574 (1994).

6 Ōmura, S. The Search for Bioactive Compounds from Microorganisms (Springer-Verlag, New York, NY, USA, 1992).

7 Iwatsuki, M. et al. Biverlactones A-D, new circumventors of arbekacin resistance in MRSA, produced by Penicillium sp. FKI-4429. Tetrahedron 67, 6644-6648 (2011).

8 Suga, T. et al. Aranorosin circumvents arbekacin-resistance in MRSA by inhibiting the bifunctional enzyme AAC(6')/APH(2"). J. Antibiot. 65, 527-529 (2012).

9 Takata, K. et al. Aogacillins A and B produced by Simplicillium sp. FKI-5985: New circumventors of arbekacin resistance in MRSA. Org. Lett. 15, 4678-4681 (2013).

10 Isaka, M., Srisanoh, U., Veeranondha, S., Choowong, W. \& Lumyong, S. Cytotoxic eremophilane sesquiterpenoids from the saprobic fungus Berkleasmium nigroapicale BCC 8220. Tetrahedron 65, 8808-8815 (2009). 
11 Verkley, G. J., Dukik, K., Renfurm, R., Göker, M. \& Stielow, J. B. Novel genera and species of coniothyrium-like fungi in Montagnulaceae (Ascomycota). Persoonia 32, 25-51 (2014).

12 Maloney, K. N. et al. Phaeosphaeride A, an inhibitor of STAT3-dependent signaling isolated from an endophytic fungus. Org. Lett. 8, 4067-4070 (2006).

13 Abraham, W. R., Meyer, H. \& Abate, D. Curvupallides, a new class of alkaloids from the fungus Curvularia pallescens. Tetrahedron 51, 4947-4952 (1995).

$14 \mathrm{Li}, \mathrm{C}$. S. et al. A new metabolite with a unique 4-pyranone- $\gamma$-lactam-1,4-thiazine moiety from a Hawaiian-plant associated fungus. Org. Lett. 17, 3356-3359 (2015).

15 Yamamoto, T. et al. Elucidation of pyranonigrin biosynthetic pathway reveals a mode of tetramic acid, fused $\gamma$-pyrone, and exo-methylen formation. Org. Lett. 17, 4992-4995 (2015).

16 Bohlmann, F. et al. Eremophilane derivatives and other constituents from Senecio species. Phytochemistry 24, 1249-1261 (1985).

17 Tori, M. et al. Diversity of Ligularia kanaitzensis in sesquiterpenoid composition and neutral DNA sequences. Tetrahedron 64, 4486-44495 (2008).
18 Cox, G., Koteva, K. \& Wright, D. G. Antibiotic adjuvants that enhance the activity of aminoglycoside against resistant strains of bacteria. The American Society for Microbiology (ASM) and the International Society of Chemotherapy (ISC) for the joint ICAAC/ICC Meeting (C-615, San Diego, CA, USA, 2015).

19 Noll, S. K., Sinko, J. P. \& Chikindas, L. M. Elucidation of the molecular mechanisms of action of the natural anitimicrobial peptide subtilosin against the bacterial vaginosisassociated pathogen Gardnerella vaginalis. Probiotics Antimicrob. Proteins 3, 41-47 (2011).

20 de Gruyter, J. et al. Redisposition of phoma-like anamorphs in Pleosporales. Stud. Mycol. 75, 1-36 (2013).

21 Tamura, K., Stecher, G., Peterson, D., Filipski, A. \& Kumar, S. MEGA6: molecular evolutionary genetics analysis version 6.0. Mol. Bio. Evol. 30, 2725-2729 (2013).

22 National Committee for Clinical Laboratory Standards. Reference Method for Performance Standards for Antimicrobial Disk Susceptibility Tests. Approved Standard 8th ed., M2-A8 (NCCLS, Wayne, PA, USA, 2003).

23 Uchida, R. et al. In vitro and in vivo anti-MRSA activities of nosokomycins. Drug Discov. Ther. 8, 249-254 (2014). 